\title{
Pseudoaneurysm complicating right ventricle-to-pulmonary artery conduit surgery: Incidence and risk factors
}

\author{
Michelle C. Sykes, MD, PhD, ${ }^{\mathrm{a}}$ Meena Nathan, MD, ${ }^{\mathrm{b}}$ Stephen P. Sanders, $\mathrm{MD},{ }^{\mathrm{c}}$ Kimberlee Gauvreau, $\mathrm{ScD},{ }^{\mathrm{a}}$ \\ Frank A. Pigula, MD, ${ }^{\mathrm{d}}$ and Jonathan Rhodes, $\mathrm{MD}^{\mathrm{a}}$
}

\section{ABSTRACT}

Objectives: Although pseudoaneurysm is an uncommon complication after right ventricle-to-pulmonary artery conduit placement, it has the potential to cause significant morbidity and mortality.

Methods: We performed a review of patients with pseudoaneurysms diagnosed at our institution in a 20-year period (from 1995 through 2015) and compared their clinical characteristics with a group of age- and sex-matched control patients.

Results: We found that younger age, smaller size, the diagnosis of tetralogy of Fallot, the use of a pulmonary homograft conduit, the presence of an unrestrictive ventricular septal defect after conduit placement, and having at least systemic right ventricular pressure were all more common in patients who had pseudoaneurysms develop.

Conclusions: This study is unique in identifying both patient and surgical factors that may predispose to pseudoaneurysm development and can help inform optimal strategies to monitor and evaluate this patient population. (J Thorac Cardiovasc Surg 2017;154:2046-9)

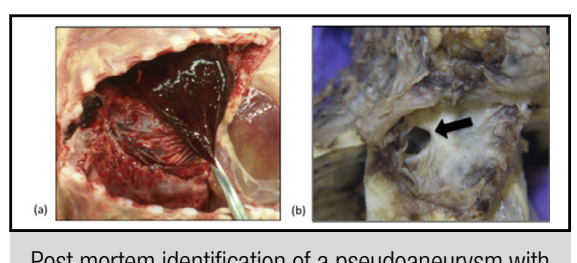

Post mortem identification of a pseudoaneurysm with evidence of suture dehiscence.

\section{Central Message}

Tetralogy of Fallot, pulmonary homograft material, unrepaired unrestrictive VSD, and systemic RV pressure are all associated with pseudoaneurysm development after RV-PA conduit placement.

\section{Perspective}

Pseudoaneurysm (PSA) is a rare complication after cardiac surgery, yet it can have significant consequences, such as compression of mediastinal structures, thromboembolism, infection, and rupture leading to death. We identified patient and surgical factors favoring PSA development after RV-PA conduit placement in children. Clinicians should be especially vigilant when faced with such risk factors.

See Editorial Commentary page 2050.
Pseudoaneurysm (PSA) is an uncommon complication of cardiac surgical procedures. When it occurs, however, it can have significant consequences, including compression of mediastinal structures, thromboembolism, infection, and even rupture resulting in death. ${ }^{1-3}$ In 1995, our institution published a review of 8 cases. Some, although not all, were associated with elevated right-sided pressures;

From the Departments of ${ }^{\mathrm{a} C}$ Cardiology and ${ }^{\mathrm{b}}$ Cardiac Surgery, and ${ }^{\mathrm{c}}$ Cardiac Registry, Department of Pediatrics, Boston Children's Hospital, Boston, Mass; and ${ }^{\mathrm{d} D e p a r t-}$ ment of Cardiovascular and Thoracic Surgery, University of Louisville School of Medicine, Louisville, Ky.

Supported by institutional review board approval: protocol IRB-P00022103, approved June 6, 2016. This work was not supported by any external or designated internal funding source.

Received for publication Oct 13, 2016; revisions received June 23, 2017; accepted for publication Aug 1, 2017; available ahead of print Sept 15, 2017.

Address for reprints: Michelle C. Sykes, MD, PhD, Division of Pediatric Cardiology, Stanford School of Medicine, 750 Welch Rd, Suite 325, Palo Alto, CA 94304 (E-mail: msykesmd@stanford.edu).

0022-5223/\$36.00

Copyright (c) 2017 by The American Association for Thoracic Surgery

http://dx.doi.org/10.1016/j.jtcvs.2017.08.014 most were ultimately thought to be of multifactorial origin. The small number of cases precluded a definitive analysis of risk factors associated with PSA formation. Since that time, only a handful of case reports have been published. ${ }^{4-7} \mathrm{We}$ sought to review our experience with this complication in the 2 decades that have elapsed since the original publication. The purpose of this undertaking was to ascertain the incidence of PSA in the current surgical era and to acquire insights into the risk factors for PSA formation, possible surgical strategies for reducing the risk of PSA formation, and effective strategies for identifying PSA in a timely manner.

- Scanning this $\mathrm{QR}$ code will take you to a supplemental video for the article. 

Abbreviations and Acronyms
PSA $=$ pseudoaneurysm
$\mathrm{RV}=$ right ventricle
$\mathrm{PA}=$ pulmonary artery

\section{MATERIALS AND METHODS}

In our study, we included patients who had development of a PSA between January 1, 1995, and December 31, 2015, after having undergone surgery at Boston Children's Hospital. We excluded patients with left-looped ventricles, patients with single-ventricle physiology, and patients whose PSA followed a catheter intervention and was thought to be possibly catheter related. Because PSA is a rare outcome, we chose a case-control design. For each patient, we randomly selected 3 control subjects who also had a right ventricle (RV)-to-pulmonary artery (PA) conduit implanted at Boston Children's Hospital. Control subjects were matched for sex, age at time of conduit placement (neonate, $<1$ month of age; infant, 1-12 months of age; child, 1-10 years of age; and adolescent to adult, $>10$ years of age), and date of surgery (within 2 years). For both case and control patients, we collected variables including gestational age, primary cardiac diagnosis, any associated syndrome, age at conduit placement, weight at conduit placement, size of the branch pulmonary arteries, surgical details (conduit type, vendor, size, use of hood, type and size of suture material), intensive care unit and hospital lengths of stay, and date of last follow-up or conduit revision (if applicable). In addition, for the case patients, we collected PSA diagnosis date, whether the condition was asymptomatic or symptomatic at the time of diagnosis, results of imaging studies, hemodynamics (including RV pressure or RV outflow tract obstruction), anatomic details of the PSA, and survival.

\section{Statistical Analysis}

For categoric variables, the Fisher exact test was used to compare case and control patients. For continuous variables, we used the Wilcoxon rank sum test. Odds ratios for PSA and their $95 \%$ confidence intervals were calculated. Although multivariable analysis was limited by the small number of outcomes, we explored relationships with case status by using exact logistic regression. Calculations were performed with GraphPad software (GraphPad Software, Inc, La Jolla, Calif).

\section{RESULTS}

During the 20-year interval under study, 24 patients who met our inclusion criteria had a PSA diagnosed that was unrelated to a catheter-based intervention. During this period, 972 RV-PA conduit operations were performed at Boston Children's Hospital. Four of the patients with PSAs had undergone surgery before 1995. These patients were therefore excluded from the calculation of the incidence of PSA formation (but were included in the analyses of risk factors). The observed incidence of PSA formation was thus 2.1\% (20/972).

The demographic and clinical features of the patients with PSAs are presented in Table 1. The patients had PSAs diagnosed from 0.5 months to 22 years after conduit placement. Most PSAs (63\%) were diagnosed within the first 6 postoperative months; the median time from conduit placement to diagnosis was only 3.7 months. Fewer than half of the patients $(46 \%)$ had symptoms at presentation, primarily respiratory symptoms (such as apnea, tachypnea, or worsening cyanosis) but also shock (there were 2 cardiac arrests); other PSAs were incidentally diagnosed on routine evaluation. Most patients
TABLE 1. Characteristics unique to patients with pseudoaneurysms diagnosed

\begin{tabular}{lc}
\hline Age at PSA diagnosis (mo) & $41.4 \pm 16.1$ (median, 5.2) \\
$\begin{array}{l}\text { Time from conduit placement to PSA } \\
\text { diagnosis (mo) }\end{array}$ & $33.7 \pm 13.8$ (median, 3.7) \\
\hline $\begin{array}{l}\text { Site of PSA } \\
\quad \text { Proximal }\end{array}$ & $22(92 \%)$ \\
$\quad$ Distal & $1(4 \%)$ \\
$\quad$ Unknown & $1(4 \%)$ \\
\hline Symptomatic presentation & $11 / 24(46 \%)$ \\
\hline $\begin{array}{l}\text { Significant CXR changes (eg, new mass, } \\
\text { tracheal deviation) }\end{array}$ & $16 / 23(70 \%)$ \\
\hline Detected on echocardiography & $18 / 24(75 \%)$ \\
\hline Detected by catheterization & $16 / 24(67 \%)$ \\
\hline Systemic or suprasystemic RV pressure (by & $16 / 22(73 \%)$ \\
$\quad$ echocardiography or catheterization) & \\
\hline Surgical intervention & $19 / 24(79 \%)$ \\
\hline Catheter intervention & $3 / 24(12 \%)$ \\
\hline Survived PSA in immediate period & $23 / 24(96 \%)$ \\
\hline$P S A$ Pseud
\end{tabular}

(70\%) had significant changes on chest radiography, most commonly including a new mass or tracheal deviation (Table 1). Only $75 \%$ of the PSAs were visualized by echocardiography (Table 1). Of the 24 patients, 16 underwent cardiac catheterization; in 2 of these cases, a previously unrecognized PSA was detected (Table 1). The RV pressure was at least systemic in most $(73 \%)$ of the patients with PSAs. In 22 of the 24 patients, the PSA was documented to have arisen proximally, from the anastomosis between the RV and the conduit.

Of the 24 patients with PSAs, 19 underwent surgical intervention for the PSA and 3 underwent catheter intervention (which included Amplatzer device [St Jude Medical, LLC, St Paul, Minn] placement within the PSA or exclusion with a covered stent or bioprosthetic valve). Of the remaining 2 patients, 1 did not undergo intervention because of tenuous status secondary to severe pulmonary vein stenosis and the other had diagnosis at autopsy of a ruptured PSA and large left hemothorax after an asystolic cardiac arrest at home.

The patients with PSAs tended to be younger $(7.7 \pm$ 2.9 months; median, 2.3 months vs $52.6 \pm 86.9$ months; median, 12.9 months; $P=.01)$ and smaller $(5.5 \pm 0.7 \mathrm{~kg}$; median, $4.7 \mathrm{~kg}$ vs $14.8 \pm 17.9 \mathrm{~kg}$; median, $8.6 \mathrm{~kg} ; P=.01)$ than those within the entire cohort who had received RV-PA conduits but had not had PSA develop. The sex distributions were statistically similar ( $38 \%$ male vs $51 \%$ female; $P=.19)$.

The clinical characteristics of the case and control patients are presented in Table 2 . The variables of prematurity, comorbid syndrome, previous cardiac surgical procedures, weight at conduit placement, use of a conduit hood, hypoplastic pulmonary arteries, intensive care unit length of stay, and hospital length of stay were not significantly different between the case and control patients. Of the 24 
TABLE 2. Characteristics of patients with pseudoaneurysms diagnosed and control patients

\begin{tabular}{|c|c|c|c|c|}
\hline Characteristic & Cases & Controls & $P$ value & Odds ratio \\
\hline Prematurity & $2 / 24(8 \%)$ & $9 / 72(13 \%)$ & .73 & $0.64(0.13-3.2)$ \\
\hline Primary diagnosis of tetralogy of Fallot & $21 / 24(88 \%)$ & $40 / 72(56 \%)$ & $<.01$ & $5.6(1.5-21)$ \\
\hline Known diagnosis of syndrome & $8 / 24(33 \%)$ & $16 / 72(22 \%)$ & .29 & $1.8(0.64-4.8)$ \\
\hline Previous cardiac surgical procedures & $5 / 24(21 \%)$ & $25 / 72(35 \%)$ & .31 & $0.50(0.17-1.5)$ \\
\hline $\begin{array}{l}\text { Age at conduit placement }(\mathrm{mo}) \\
\text { Mean } \pm \mathrm{SE} \\
\text { Median }\end{array}$ & $\begin{array}{c}7.6 \pm 2.8 \\
2.3\end{array}$ & $\begin{array}{l}9.5 \pm 1.7 \\
4.4\end{array}$ & .33 & $0.89(0.58-1.4) *$ \\
\hline $\begin{array}{l}\text { Weight at conduit placement }(\mathrm{kg}) \\
\text { Mean } \pm \mathrm{SE} \\
\text { Median }\end{array}$ & $\begin{array}{c}5.5 \pm 0.7 \\
4.7\end{array}$ & $\begin{array}{l}5.6 \pm 0.4 \\
4.5\end{array}$ & .99 & $0.97(0.48-2.0) \dagger$ \\
\hline Pulmonary homograft & $15 / 24(63 \%)$ & $26 / 72(36 \%)$ & .03 & $2.9(1.1-7.7)$ \\
\hline Use of conduit hood & $22 / 24(92 \%)$ & $57 / 71(80 \%)$ & .34 & $2.7(0.57-13)$ \\
\hline Hypoplastic PA size & $14 / 24(58 \%)$ & $30 / 72(42 \%)$ & .17 & $2.0(0.77-5.0)$ \\
\hline Postoperative unrestrictive VSD & $11 / 24(46 \%)$ & $10 / 72(14 \%)$ & $<.01$ & $5.3(1.8-15)$ \\
\hline Postoperative systemic or greater RV pressure & $12 / 20(60 \%)$ & $12 / 41(29 \%)$ & .03 & $3.6(1.2-11)$ \\
\hline $\begin{array}{l}\text { ICU LOS }(\mathrm{d}) \\
\quad \text { Mean } \pm \mathrm{SE} \\
\quad \text { Median }\end{array}$ & $\begin{array}{c}10 \pm 2 \\
9\end{array}$ & $\begin{array}{r}16 \pm 3 \\
9\end{array}$ & .49 & - \\
\hline $\begin{array}{l}\text { Total hospital LOS (d) } \\
\text { Mean } \pm \text { SE } \\
\text { Median }\end{array}$ & $\begin{array}{c}23 \pm 6 \\
17\end{array}$ & $\begin{array}{r}23 \pm 3 \\
15\end{array}$ & .56 & - \\
\hline
\end{tabular}

Continuous variables are summarized both as mean \pm SE and as median and are compared with the Wilcoxon rank sum test. Categoric variables are compared with the Fisher exact test. Odds ratios are presented with $95 \%$ confidence intervals in parentheses. $S E$, Standard error; $P A$, pulmonary artery; $V S D$, ventricular septal defect; $R V$, right ventricle; $I C U$, intensive care unit; LOS, length of stay. *Per 12-month increase. †Per 5-kg increase.

case patients with PSA, $15(62.5 \%)$ received pulmonary homografts and $9(37.5 \%)$ received aortic homografts. In contrast, of the 72 control subjects, $26(36 \%)$ received pulmonary homografts, $41(57 \%)$ received aortic homografts, and 5 received other conduits $(7 \% ; 4$ bovine jugular vein and 1 GORE-TEX tube [W. L. Gore \& Associates, Inc, Flagstaff, Ariz]). Among the pulmonary homografts inserted, there were 5 SynerGrafts (CryoLife, Inc, Kennesaw, Ga), all inserted after January 2013 (after the manufacturer had modified the processing of the homograft in response to concerns regarding the tissue integrity of the product). One of these 5 patients had a PSA develop.

It was possible to identify the suture material used in 19 of 24 patients with PSAs and in 61 of 72 control subjects. Prolene (Ethicon Inc, Somerville, NJ) was used in all identifiable cases, and the size of the suture material used for the patients with PSAs was invariably identical to or within 1 United States Pharmacopeia size of that used in the control subjects. Furthermore, neither the identity of the conduit vendor nor the individual surgeon was significantly associated with PSA development. In contrast, the diagnosis of tetralogy of Fallot (including all subtypes; odds ratio, 5.6; 95\% confidence interval, 1.5-21), the use of a pulmonary homograft for the RV outflow tract reconstruction (odds ratio, 2.9; $95 \%$ confidence interval, 1.1-7.7), the presence of an unrestrictive ventricular septal defect (odds ratio, 5.3; 95\% confidence interval, 1.8-15), and postoperative systemic or suprasystemic RV pressure (odds ratio, 3.6; 95\% confidence interval, 1.2-11) were all significant variables favoring PSA development. Other details of surgical technique were generally not mentioned in the operative report or were not described in detail sufficient to permit reliable statistical analysis. On multivariable analysis, use of a pulmonary homograft (odds ratio, 5.3; $P<.01$ ) and presence of an unrestrictive ventricular septal defect (odds ratio, 9.0; $P=.01$ ) were independently associated with PSA development.

\section{DISCUSSION}

To our knowledge, this is the largest review of PSAs complicating RV-PA conduit surgery. Although this complication has a low incidence, the potential for morbidity and mortality are high. For a brief discussion, please see Video 1. Almost half of the patients had symptoms at the time of presentation. There were 2 cardiac arrests and 1 death.

From our analysis, we identified younger age, smaller size, and several other factors, both patient and surgical, that favored the development of a PSA. These included the use of a pulmonary homograft and conditions associated with elevated RV pressure including an unrestrictive ventricular septal defect after conduit placement, postoperative systemic or greater RV pressure, and the underlying diagnosis of tetralogy of Fallot (relative to truncus arteriosus, tetralogy of Fallot is more likely to be associated with significant branch or peripheral PA stenosis, and patients with tetralogy of Fallot are therefore more 


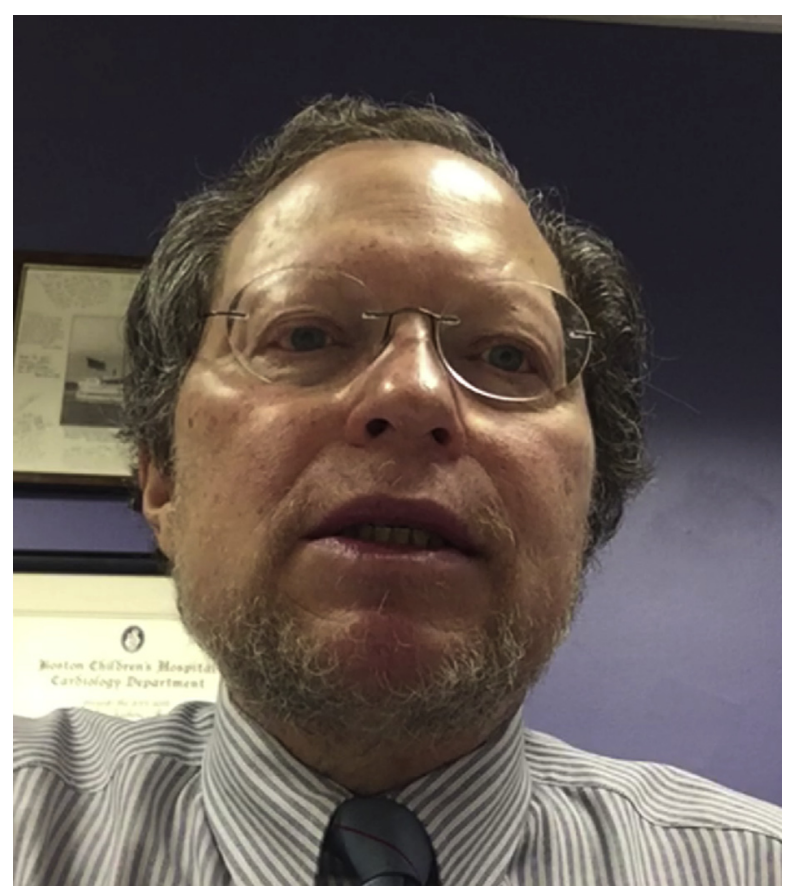

VIDEO 1. J.R. discusses the findings and relevance of the article. Video available at: http://www.jtcvsonline.org/article/S0022-5223(17)31763-4/fulltext.

likely to have postoperative RV hypertension). We believe that clinicians should be especially vigilant for the development of a PSA in patients with these risk factors. High quality imaging studies focusing on the RV outflow tract should be obtained at a frequency greater than that employed for other patients who have undergone RV-PA conduit operations. Specifically, because more than half of the patients with PSAs had no symptoms, and the ability of chest radiography or echocardiography to detect this potentially life-threatening complication was suboptimal (sensitivity $<75 \%$ ), we believe that it would be reasonable for clinicians to undertake a cardiac computed tomographic scan 4 to 6 weeks postoperatively and perhaps again 4 to 6 months postoperatively in patients at high risk for PSA development. We believe it likely that, relative to a chest radiograph or echocardiogram, a computed tomographic scan will be more capable of reliably detecting the presence of a pseudoaneurysm. Moreover, with recent advances in computed tomographic technology, these scans can often be acquired without general anesthesia and with less radiation than in the past. ${ }^{8}$ In addition, because almost all the PSAs developed at the anastomosis between the RV and the conduit, measures to reinforce this anastomosis at the time of surgery should be considered, especially in patients with risk factors for PSA development. In some patients, out of concern regarding hypoplasia of the pulmonary arteries, stiff materials such as GORE-TEX are generally avoided to promote anastomotic patency, and homograft tissue replacements are generally favored. In light of our findings, however, alternatives to a pulmonary homograft should be considered. Aortic homografts, or even cryopreserved saphenous or femoral vein grafts, have been used successfully and may be more appropriate choices in high-risk candidates. Furthermore, we speculate that given the location of many aneurysms at the RVhomograft suture line, limiting the size of the ventriculotomy could also be of benefit. Further studies are needed to determine whether these or other measures reduce the incidence and consequences of this rare but serious complication of RV-PA conduit surgery.

\section{Limitations}

This study was somewhat limited by the small number of cases and by the case-control study design. Although this represents the largest review to date, the number of cases was inherently low because of the rarity of congenital heart diseases requiring RV-PA conduit placement and the rarity of postoperative PSA formation. In addition, not all medical records were complete, particularly for cases diagnosed in the 1990s. It also must be recognized that that the true incidence of postoperative PSA may be higher than the $2.1 \%$ observed in this study. Many of the identified PSAs were asymptomatic and only incidentally diagnosed; other undiagnosed cases likely exist within the cohort that was studied. Finally, we recognize that the relatively small number of PSA cases and the fact that only 1 patient in our series is known to have died of a PSA complication make it impossible to use our data to undertake a meaningful cost-benefit analysis of diagnostic or therapeutic interventions in patients with PSAs. Nevertheless, we believe that it is reasonable to consider patients with PSAs to be at increased risk for catastrophic events, and we therefore believe that an aggressive approach to diagnosis and intervention is warranted.

\section{Conflict of Interest Statement}

Authors have nothing to disclose with regard to commercial support.

\section{References}

1. Antal AD, Cikirikcioglu M, Myers PO, Didier D, Kalangos A. Respiratory distress after surgery of RVOT pathologies: a word of caution on pseudoaneurysm development. Thorac Cardiovasc Surg. 2010;58:356-8.

2. Kaza AK, Lim HG, Dibardino DJ, Bautista-Hernandez V, Robinson J, Allan C, et al Long-term results of right ventricular outflow tract reconstruction in neonatal cardiac surgery: options and outcomes. J Thorac Cardiovasc Surg. 2009;138:911-6.

3. Levine JC, Mayer JE, Keane JF, Spevak PJ, Sanders SP. Anastomotic pseudoaneurysm of the ventricle after homograft placement in children. Ann Thorac Surg. 1995;59:60-6.

4. Herbert C, Ikemba C, Nugent A. Device closure of a pseudoaneurysm of the righ ventricular outflow tract in an infant with right ventricle-to-pulmonary artery homograft. Catheter Cardiovasc Interv. 2014;83:587-90.

5. Maxwell BG, Wise-Faberowski L. Management of high-risk reentry sternotomy in an infant for repair of a giant pseudoaneurysm of the right ventricular outflow tract. Ann Card Anaesth. 2014;17:59-61.

6. Pillai SK, Reddy HPS, Kulknarni S, Murthy KS, Cherian KM. Pseudoaneurysm of homograft placed in right ventricular outflow tract. Ann Thorac Surg. 2004;78:1068-70.

7. Sadiq M, Fenton AC, Firmin RK. False aneurysm of the right ventricular outflow tract after total correction of tetralogy of Fallot: diagnosis by echocardiography and successful repair by neck cannulation for cardiopulmonary bypass. Br Heart J. 1994;71:566-8.

8. Kubo T, Ohno Y, Kauczor HU, Hatabu H. Radiation dose reduction in chest CTreview of available options. Eur J Radiol. 2014;83:1953-61.

Key Words: conduit, pseudoaneurysm, tetralogy of Fallot 